\title{
Uterine flushings from women treated with levonorgestrel affect sperm functionality in vitro
}

\author{
Mayel Chirinos ${ }^{1,}$, , Marta Durand ${ }^{1,}$, , María Elena González-González ${ }^{1}$, Gabriela Hernández- \\ Silva ${ }^{1}$, Israel Maldonado-Rosas ${ }^{2,+}$, Pablo López ${ }^{2}$ and Fernando Larrea ${ }^{1}$ \\ ${ }^{1}$ Departamento de Biología de la Reproducción Dr Carlos Gual Castro, Instituto Nacional de Ciencias Médicas y \\ Nutrición Salvador Zubirán, Mexico City, Mexico and ${ }^{2}$ Instituto Mexicano de Alta Tecnología Reproductiva \\ (Inmater), Mexico City, Mexico \\ Correspondence should be addressed to F Larrea; Email: fernando.larreag@incmnsz.mx \\ *(M Chirinos and M Durand contributed equally to this work) \\ ${ }^{\dagger}$ (I Maldonado-Rosas is now at Centro de Innovación Tecnológica y Medicina Reproductiva (Citmer), Mexico City, Mexico)
}

\begin{abstract}
Levonorgestrel (LNG), a synthetic 19 nor-testosterone derivative, is widely used for emergency contraception. It is well known that LNG prevents ovulation only when given prior to the surge of serum luteinizing hormone (LH) during the periovulatory phase of the menstrual cycle. This observation suggests that LNG, given its contraceptive efficacy, has additional effects other than those affecting ovulation. In this study, we have evaluated the effects on human sperm functionality of uterine flushings (UF) obtained from women at day $\mathrm{LH}+1$ of a control cycle $(\mathrm{CTR}-\mathrm{LH}+1)$ and after receiving LNG $(\mathrm{LNG}-\mathrm{LH}+1)$ two days before the surge of $\mathrm{LH}$. Human sperm from normozoospermic donors were incubated with UF and protein tyrosine phosphorylation, sperm motility, acrosome reaction as well as zona pellucida (ZP) binding capacity were assessed. A significant decrease in total motility and tyrosine phosphorylation accompanied by an increase on spontaneous acrosome reaction was observed when sperm were incubated in the presence of LNG-LH + 1. None of these effects were mimicked by purified glycodelin A (GdA). Moreover, the addition of UF obtained during the periovulatory phase from LNG-treated women or the presence of purified GdA significantly decreased sperm-ZP binding. The data were compatible with changes affecting sperm capacitation, motility and interaction with the ZP. These results may offer evidence on additional mechanisms of action of LNG as an emergency contraceptive.

Reproduction (2017) 154 607-614
\end{abstract}

\section{Introduction}

Levonorgestrel (LNG), a 19 nor-testosterone derived synthetic progestin, is widely used for emergency contraception. Several groups have demonstrated that LNG administration during the follicular phase delays or inhibits the midcycle preovulatory surge of luteinizing hormone (LH) leading to anovulation (Durand et al. 2001, 2010, Croxatto et al. 2004). However, supplementary mechanisms have also been proposed to support its contraceptive efficacy. Induction of changes by LNG within the female reproductive tract may detrimentally affect gamete physiology and fertilization. For instance, sperm capacitation is a process involving a series of modifications that enables sperm to fertilize (Aitken \& Nixon 2013). Since this process is modulated by molecules present in the female reproductive tract (De Jonge 2005), it is likely that changes in the uterotubal secretions may in turn affect sperm physiology and therefore fertilization.
Besides its pregnancy promoting properties, progesterone $(\mathrm{Pg})$ is the best known regulator of sperm capacitation in the female genital tract (DasGupta et al. 1994, Kay et al. 1994). Due to its Pg-like activity, LNG may act as Pg on sperm after binding to progesterone receptors and to CatSper calcium channels (Aquila \& De Amicis 2014). Indeed, previous investigations have shown that LNG induces dose-response effects on sperm physiology (Yeung et al. 2002, Bahamondes et al. 2003). However, no clear evidence exists on LNGmediated effects through changes in the female reproductive tract that could affect sperm functionality. Among the few studies on this regard, it is known that the administration of LNG to normal cycling women or through a LNG-releasing intrauterine device increases serum and uterine glycodelin A (GdA) concentrations (Mandelin et al. 1997, Durand et al. 2005). Interestingly, GdA of endometrial source is shown to inhibit spermatozoa binding to the zona pellucida (ZP) in vitro 
(Oehninger et al. 1995). These observations suggest that the ability of LNG to induce environmental changes in the female genital tract, when given at the time of ovulation, might probably account for its contraceptive efficacy, particularly in those women remaining ovulatory after LNG treatment. The general aim of this study was to investigate the effects of uterine flushings (UF) obtained from control and LNG-treated cycles at the time of ovulation on several physiological parameters of human spermatozoa, including their binding to ZP.

\section{Materials and methods}

\section{Participants}

The study was approved by the Human Ethical and Scientific Review Committee of the Instituto Nacional de Ciencias Médicas y Nutrición Salvador Zubirán and all participants signed an informed consent form. Six healthy women in reproductive age, without pregnancy risk and with regular menstrual cycles between 25 and 34 days volunteered to participate in this study. None used hormonal contraceptives or any other medication within 6 months prior their admission to the study. Participants were in good health as determined by medical history, physical examination, and routine screening laboratory tests. Each woman recorded details of bleeding episodes throughout the study.

\section{Study design}

All participants were admitted during the first 10 days of their menstrual cycle. In the treated cycle, each woman received during the preovulatory phase $1.5 \mathrm{mg}$ of LNG (Glanique; Asofarma de México, SA de CV, Mexico), divided into two doses $12 \mathrm{~h}$ apart, approximately two days before LH surge and corresponding to a leading follicle diameter between 16 and $19 \mathrm{~mm}$ as measured by transvaginal ultrasound. Women who did not present positive LH in urine during control cycles were excluded from the study. UF were obtained by insertion of an intrauterine insemination catheter (CORNE, SA de CV, Mexico) into the uterine cavity in order to flush $10 \mathrm{~mL}$ of physiological saline solution, that was followed by careful aspiration of the fluid with a 20-cc syringe. Aspiration procedure was repeated at least three times to ensure maximal sample recovery (Durand et al. 2010). The UF were obtained at the time of follicle rupture (day $\mathrm{LH}+1)$ in control and treated cycles and day $\mathrm{LH}+12$ in control cycles only. All samples were stored at $-35^{\circ} \mathrm{C}$ until assayed.

\section{Hormone and $G d A$ assays}

$\mathrm{LH}$ in urine was monitored by a commercially available kit (Ovuquick, Corne SA de CV, Mexico). Concentrations of Pg in UF were measured in duplicate by specific radioimmunoassay using commercial reagents (Diagnostic Products Corporation, Los Angeles, CA, USA). GdA concentrations in UF were determined by a sandwich-type immunofluorometric assay as previously described (Durand et al. 2010). Its presence in UF was further investigated by Western blot analysis, using as primary antibody a monoclonal mouse anti-human GdA (Abcam) diluted 1:500, followed by a HRP-conjugated goat anti-mouse IgG. Antigen-antibody complexes were visualized by enhanced chemiluminescence (ECL; GE Healthcare) and images were acquired with a Chemi Doc XRS + Imaging System (Bio-Rad).

\section{Semen samples processing for in vitro studies}

Semen samples were obtained by masturbation from normozoospermic voluntary donors with 3-5 days of sexual abstinence. Ejaculates were allowed to liquefy at $37^{\circ} \mathrm{C}$ for $30 \mathrm{~min}$ and assessed using standard methods (World Health Organization 1999). Semen aliquots of $0.25 \mathrm{~mL}$ were carefully overlaid with $0.8 \mathrm{~mL}$ of Hanks' Balanced Salt Solution (HBSS, without sodium bicarbonate) and incubated during $1 \mathrm{~h}$ at $37^{\circ} \mathrm{C}$, in an atmosphere of $5 \% \mathrm{CO}_{2}$ in air with the tubes inclined at an angle of $45^{\circ}$, for swim-up separation. The uppermost $0.75 \mathrm{~mL}$ fractions with motile sperm were recovered and re-assessed for motility and concentration.

\section{Sperm function analysis}

Sperm samples, adjusted to 40,000 spermatozoa/ $\mu \mathrm{L}$, were incubated during $3 \mathrm{~h}$ at $37^{\circ} \mathrm{C}$ in the absence or presence of control or LNG-treated UF $(0.5 \mathrm{mg} / \mathrm{mL}$ protein final concentration, diluted with HBSS) obtained at day $\mathrm{LH}+1$ $(\mathrm{CTR}-\mathrm{LH}+1$ and $\mathrm{LNG}-\mathrm{LH}+1)$ and day $\mathrm{LH}+12$ or in the absence or presence of different concentrations of GdA diluted with capacitating medium (Human Tubal Fluid medium (Irvine Scientific, Santa Ana, CA, USA), supplemented with $0.3 \%$ human serum albumin and sodium pyruvate $1 \mathrm{mM}$ ). Pure GdA was kindly donated by Drs Markku Seppala and Riitta Koistinen and prepared from human amniotic fluid collected at 15-16 weeks of gestation (Riittinen et al. 1991). Amniotic fluid was dialyzed against $50 \mathrm{mM} \mathrm{NH}_{4} \mathrm{HCO}_{3} \mathrm{pH} 8.3$ and fractionated at room temperature on a DEAE-Sepharose CL-6B column with a linear $\mathrm{NH}_{4} \mathrm{HCO}_{3}$ gradient $(50-400 \mathrm{mM})$ $\mathrm{pH} 8.3$, containing $2 \%$ isopropanol. Afterwards, sample was filtrated on a Sephadex G-100 column equilibrated with $20 \mathrm{mM}$ sodium phosphate buffer, $\mathrm{pH}$ 8.0. Finally, sample was subjected to anion exchange chromatography using a gradient of $20-92 \mathrm{mM}$ sodium phosphate, $\mathrm{pH}$ 8.0, containing $0.5 \%$ isopropanol, dialyzed against PBS, lyophilized and stored until use.

The effects of UF and GdA on sperm function were examined by protein tyrosine phosphorylation, sperm motility and acrosome reaction. Additionally, for all experimental conditions tested, cell viability was assessed at the end of incubations by the trypan blue dye exclusion test. Tyrosine phosphorylation was evaluated by Western blots as previously described (Lopez-Torres et al. 2017). Immunodetection was performed using a monoclonal antibody against phosphotyrosine residues (anti-pY, 1:10,000, clone 4G10; Millipore). After three washes, membranes were incubated in the presence of HRP-conjugated anti-mouse IgG $(1: 4000)$ and detection was performed by enhanced chemiluminescence. Homogeneous protein loading was checked by re-probing membranes with a polyclonal anti- $\beta$-tubulin as primary antibody (anti-tub; 
Sigma-Aldrich) and densitometry analyses were performed using the ImageJ software. Results were expressed as the relative density of phosphotyrosine/ $\beta$-tubulin (pY/tub) and values obtained in the absence of UF or GdA were arbitrarily set as 1 to normalize each experiment. For motility assessments, $10 \mu \mathrm{L}$ aliquots of incubated sperm samples were analyzed under a phase contrast microscope at $\times 400$ magnification and spermatozoa motility was classified as progressive, non-progressive or immotile according to WHO criteria (World Health Organization 1999). The percentage of spermatozoa motility was determined as described before (Caballero-Campo et al. 2006). Acrosome reaction was assessed in $10 \mu \mathrm{L}$ aliquots of incubated sperm. After washing with PBS, samples were fixed in 70\% ethanol and smeared on poly-L-lysine pre-treated slides. Subsequently, spermatozoa were incubated with rabbit polyclonal antibodies against acrosin (Santa Cruz Biotechnologies), diluted 1:50 in $1 \%$ PBS-BSA. Immunocomplexes were visualized by the use of a FITC-labeled goat anti-rabbit IgG (Zymed, San Francisco, CA, USA). The percentage of acrosome-reacted sperm was determined after double blinded scoring of at least 200 cells under a fluorescence microscope (Gallo et al. 1991).

\section{Hemizona assay}

The hemizona binding assay was performed as previously described (Burkman et al. 1988, Saldivar-Hernandez et al. 2015). Briefly, unfertilized oocytes from women undergoing ovarian stimulation for assisted reproduction treatments were used as the source of $\mathrm{ZP}^{\prime} \mathrm{s}$ that were micro-bisected into two equal hemizonae in capacitating medium. On the other hand, sperm samples were processed as described above, incubated for $4 \mathrm{~h}$ under capacitating conditions and further preincubated for $30 \mathrm{~min}$ in either control or test UF $(\mathrm{CTR}-\mathrm{LH}+1$ and LNG-LH+1 respectively). Each ZP half was incubated with $5-7 \times 10^{4}$ control or test pre-treated spermatozoa for $4 \mathrm{~h}$ at $37^{\circ} \mathrm{C}$ in an atmosphere of $5 \% \mathrm{CO}_{2}$ in air. After washing by vigorous pipetting in fresh medium, the numbers of tightly bound spermatozoa on the outer surface of the hemizonae were counted under a phase-contrast microscope. The results were expressed as the hemizona index $(\mathrm{HZI})$, defined as the ratio of the number of test spermatozoa bound to one hemizona to the number of control spermatozoa bound to the matching half multiplied by 100 . As a control, parallel hemizona assays were performed using GdA-pre-treated spermatozoa or sperm without pre-treatment in capacitating medium.

\section{Statistical analysis}

Data are presented as means \pm S.E.M. Experimental groups were compared using ANOVA and the Tukey's multicomparison test as post hoc test using the GraphPad Prism 5.0 software. For hemizona experiments, data are expressed as mean \pm S.D. and differences were established by the paired sample t-test. A probability value $<0.05$ was considered statistically significant.
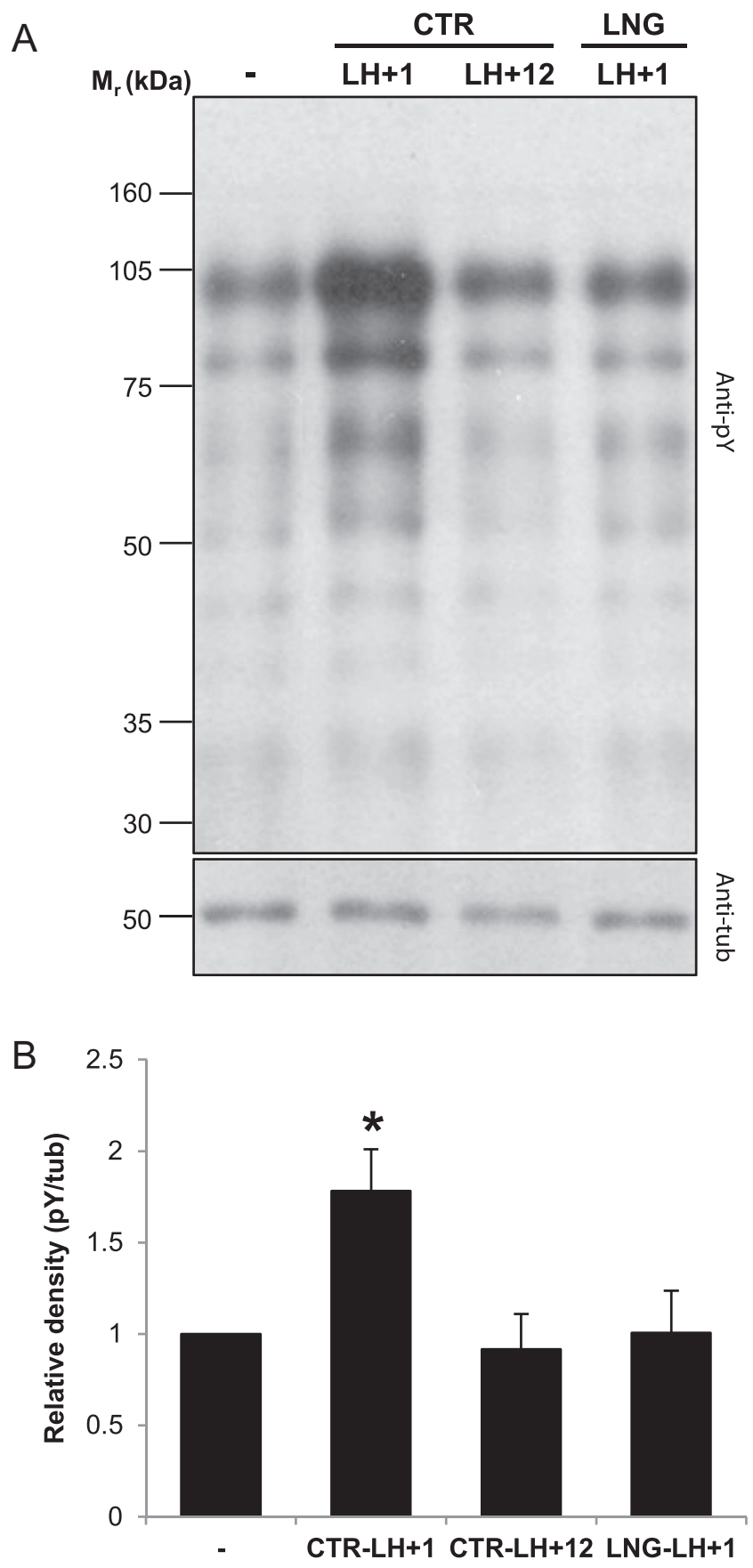

Figure 1 Effects of UF on sperm proteins tyrosine phosphorylation. Spermatozoa incubated in the absence (-) or presence of UF obtained during control (CTR-LH+1, CTR-LH+12) or LNG-treated (LNG-LH+1) cycles were analyzed. (A) Representative Western blots of a sperm sample treated with UF from one woman and probed with anti-phosphotyrosine (pY) and anti- $\beta$-tubulin (tub). (B) Relative pY/tub density signal after densitometric analysis of Western blots, where incubations in the absence of UF (-) were used for values normalization in each experiment. Data are expressed as the mean \pm S.E.M., $n=4$. ${ }^{*} P<0.05$ vs absence (-) of UF. 


\section{Results}

\section{Menstrual cycle and sperm sample characteristics}

In all cases, follicular rupture took place with no significant differences between control and LNG-treated cycles. However, treatment with LNG two days before LH surge reduced the mean cycle length at expenses of shortening the luteal phase duration. Analysis of semen samples from donors, particularly sperm morphology, motility and sperm concentration, were in agreement to normal reference values according to the WHO guidelines.

\section{Effects of UF on sperm function}

The main outcome variables studied on sperm samples treated with UF from control or treated cycles were sperm viability, protein tyrosine phosphorylation, sperm motility and spontaneous acrosome reaction.

Sperm protein tyrosine phosphorylation was used as a marker of sperm capacitation and changes in this parameter were evaluated by Western blots. Figure 1 shows the immunostaining pattern (panel A) and densitometric analysis (panel B) of proteins resulting when sperm were incubated in the presence of UF from control or LNG-treated cycles. As shown, a clear and significant increase in tyrosine phosphorylation was observed when sperm were incubated with UF from control cycles at day $\mathrm{LH}+1(\mathrm{CTR}-\mathrm{LH}+1)$ when compared to the negative control incubation in the absence of UF. In contrast, UF from LNG-LH +1 - and CTR-LH+12-treated cycles did not stimulate protein tyrosine phosphorylation, displaying similar intensities to that obtained in the absence of UF. No immunoreactivity was observed when Western blots were incubated in the absence of the primary antibody (data not shown).

Motility, a remarkable variable of functional sperm, was studied after incubations of sperm samples in the presence of UF obtained at the day $\mathrm{LH}+1$ and $\mathrm{LH}+12$ in control cycles (CTR-LH+1, CTR-LH+12) or with UF from LNG-treated cycles at day LH+1 (LNG-LH+1). As depicted in Fig. 2, incubations of cells in the presence of UF from LNG-LH+1 resulted in a significant increase of the immotile sperm fraction when compared to incubations in the presence of UF from CTR-LH+1 (from $30 \%$ to $49 \%$ ). This increase was at the expense of the progressive sperm fraction as non-progressive sperm percentages remained unaltered. No significant effects were observed on motility with UF from CTR-LH +12 or in the absence of UF when compared to CTR-LH +1 .

Incubations with UF obtained from LNG-LH+1 resulted in a significant increase in the acrosome reaction rate when compared to spermatozoa incubated in the absence of UF $(40.7 \%$ vs $20.1 \%, P<0.05)$ (Fig. 3A), while no differences were observed in the presence of $\mathrm{CTR}-\mathrm{LH}+1$ or CTR-LH+12. As Pg is a natural agonist of sperm acrosome reaction and therefore may be

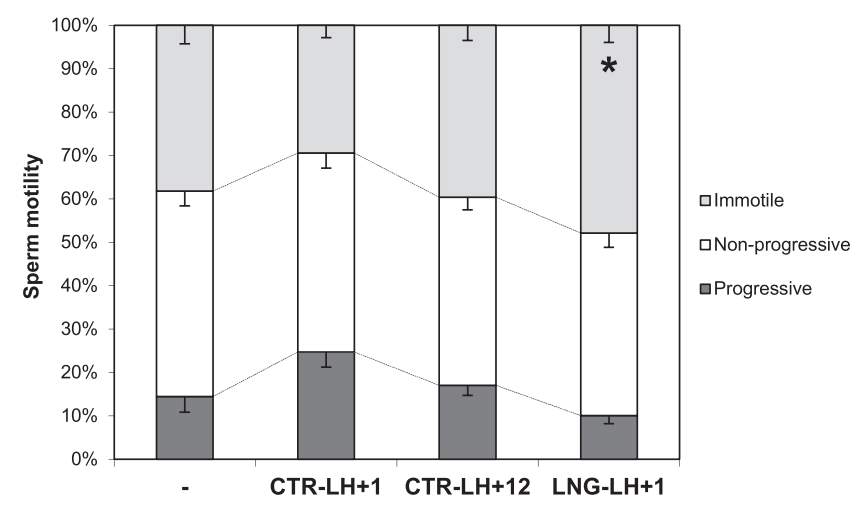

Figure 2 Motility analysis of sperm treated with UF. Spermatozoa were incubated in the absence (-) or presence of UF and manual motility assessment was performed to determine the percentages of progressive motility (dark gray bars), non-progressive motility (white bars) and immotility (light gray bars). Data are expressed as the mean \pm S.E.M., $n=20 .{ }^{*} P<0.05$ vs CTR-LH +1 .

responsible of the acrosome reaction increase observed in the presence of LNG-CTR +1 , the concentrations of this hormone in the UF were assessed (Fig. 3B).
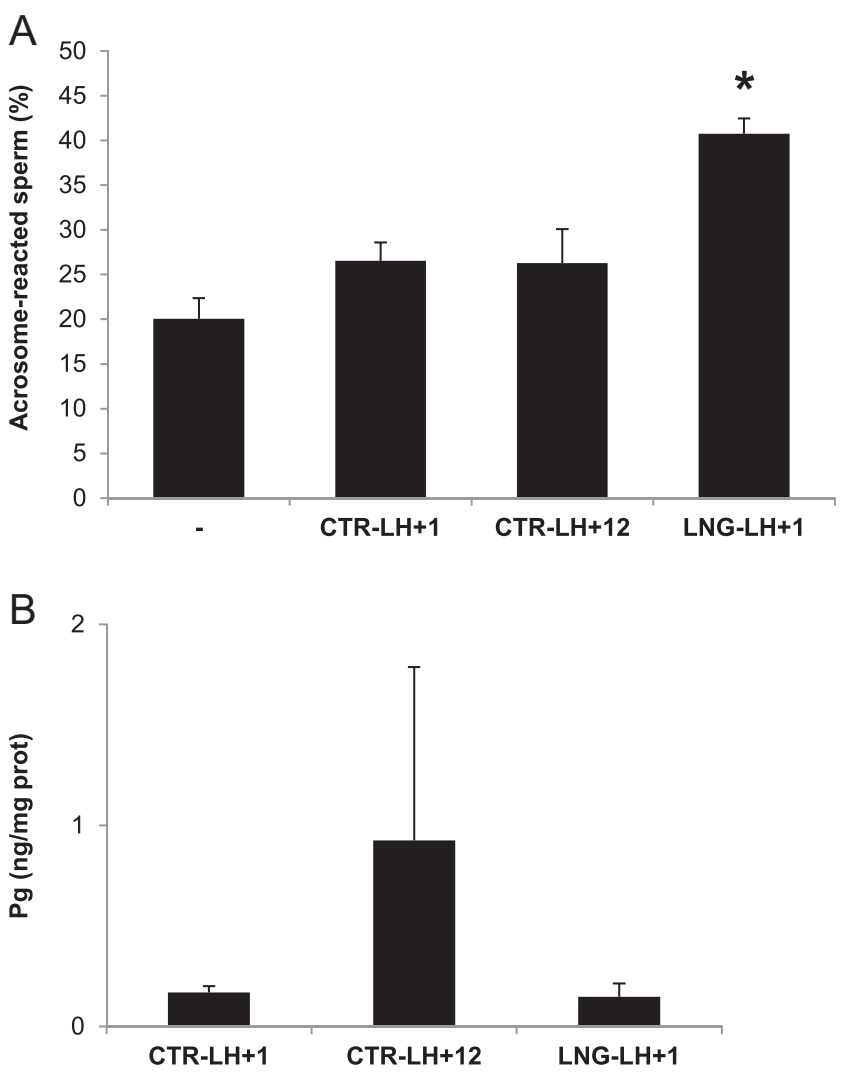

Figure 3 Acrosome reaction of sperm incubated with UF. (A) Spermatozoa incubated in the absence $(-)$ or presence of UF were evaluated to determine the percentage of acrosome-reacted sperm, $n=18 ;{ }^{*} P<0.05$ vs absence (-) of UF. (B) Progesterone (Pg) concentrations in control and LNG-treated UF, $n=6$. Data are expressed as the mean \pm S.E.M. 
No significant differences in the Pg content of the UF were observed, indicating that Pg was not involved in the acrosome reaction induction observed in the presence of $\mathrm{LNG}-\mathrm{LH}+1$.

Under all experimental conditions, sperm viability was similar in the presence or absence UF obtained from control or LNG-treated cycles. Viability values were always above $90 \%$.

\section{Effects of LNG administration on GdA content in UF obtained}

In LNG-treated cycles, the concentration of immunoassayable GdA in UF taken three days after the administration of the drug was significantly higher than that observed in CTR-LH $+1(297 \pm 200$ vs $4.66 \pm 1.72 \mathrm{ng} / \mathrm{mg}$ of protein respectively; $P<0.05)$. Besides, CTR-LH +12 also showed an anticipated significant increase in GdA concentrations when compared to CTR-LH+1 (Fig. 4A). In addition, we analyzed UF from CTR-LH + 1, CTR-LH +12 and LNG-LH +1 by Western blots using a specific primary antibody against human GdA (Fig. 4B). As can be seen, preovulatory administration of LNG was accompanied by an increase of GdA in UF from LNG-LH+1. As expected, and used as an internal control, the presence of GdA was particularly high in UF from CTR-LH+12. It is also shown that the immunoreactive bands had an electrophoretic mobility with apparent $\mathrm{Mr}$ of approximate $26 \mathrm{kDa}$, similar to that of the pure human GdA standard preparation.

\section{Effects of GdA on sperm physiology parameters}

In order to investigate whether the GdA present in UF from LNG-treated cycles may account for the described effects on sperm parameters, we incubated spermatozoa in the presence or absence of increasing concentrations of a purified preparation of human GdA. As shown in Fig. 5, none of the GdA concentrations tested affected in a significant manner protein tyrosine phosphorylation (A), total sperm motility (B) or the percentages of acrosome-reacted sperm $(C)$.

\section{Effects of UF and GdA on sperm-ZP interaction}

As GdA is found to inhibit the binding of spermatozoa to $\mathrm{ZP}$, we investigated if UF from LNG-LH +1 could affect the sperm-ZP interaction. A significant $42 \%$ decrease in the hemizona index was observed in the presence of UF from LNG-LH+1 when compared to CTR-LH+1 (Fig. 6). A pure GdA preparation was also used as a positive control of the assay, showing the anticipated reduction in sperm-ZP binding.

\section{Discussion}

Fertilization is the result of a series of crucial steps that ends in successful interaction of a sperm with an oocyte.
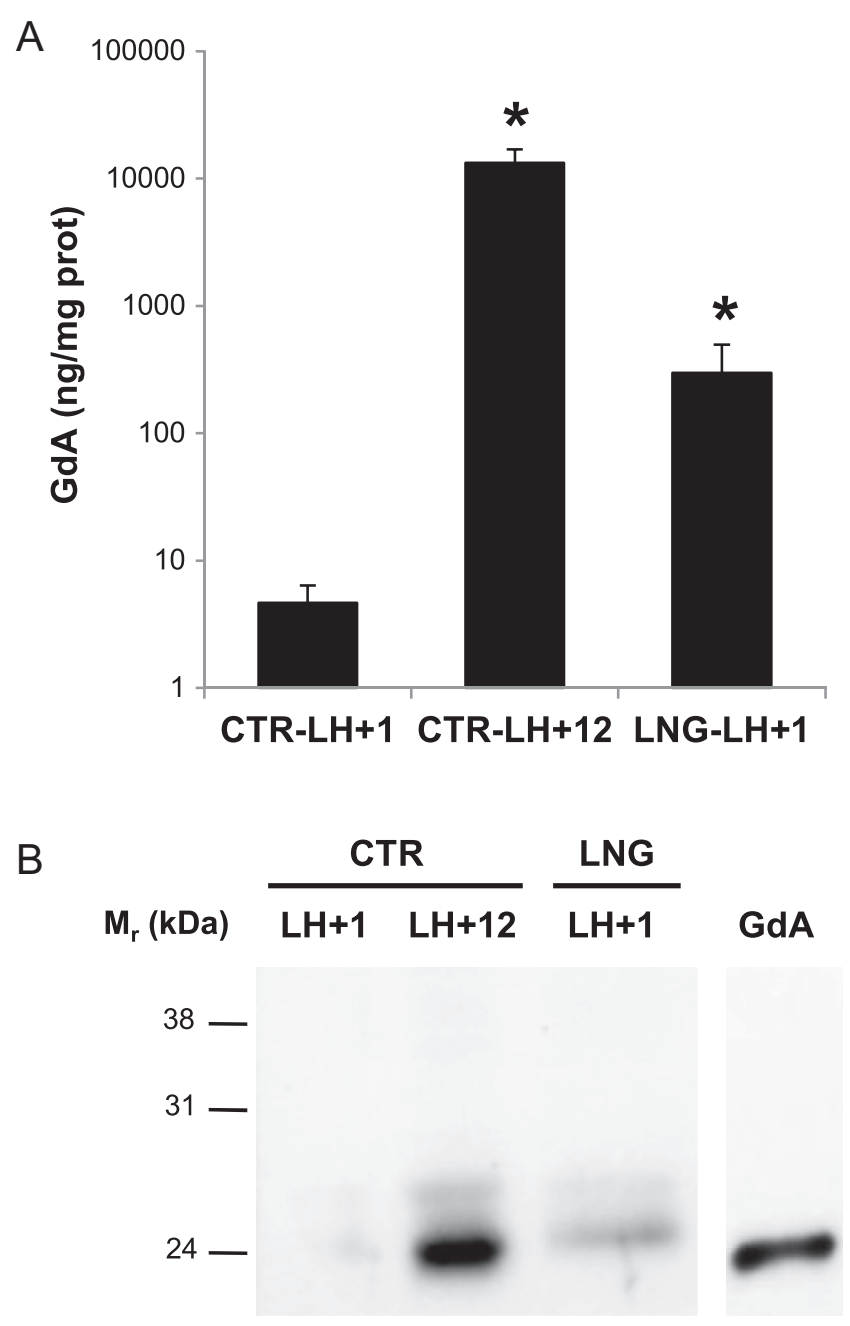

Figure 4 Presence of GdA in UF. (A) Glycodelin A (GdA) concentrations in CTR and LNG-treated UF. Results are expressed as the mean \pm S.E.M., $n=6$; ${ }^{*} P<0.05$ vs CTR-LH +1 . (B) Representative Western blot to characterize the presence of GdA in CTR and LNG-treated UF obtained from a woman during the periovulatory phase of the cycle $(\mathrm{LH}+1)$. Positive controls are also shown (CTR-LH+12 and pure GdA).

This process comprises sperm transport from the cervix to the oviduct ampulla, interactions with the cumulus oophorus, including ZP binding and penetration, and finally, fusion of the sperm with the oocyte. This entire pathway is regulated by molecules produced and secreted in the female reproductive tract (Kirton \& Hafs 1965). Previous investigations indicated that reproductive fluids such as follicular fluid (Caille et al. 2012) and human oviductal tissue-conditioned medium (Zumoffen et al. 2010) modulate sperm capacitation, and in the porcine model, such modulation diverges whether sperm are exposed to pre-, peri- or post-ovulation oviductal fluids (Tienthai et al. 2004). In this study, we tried to understand how a preovulatory-given progestin may or may not affect sperm physiology by exposing these cells to secretions from the female internal genital tract. 

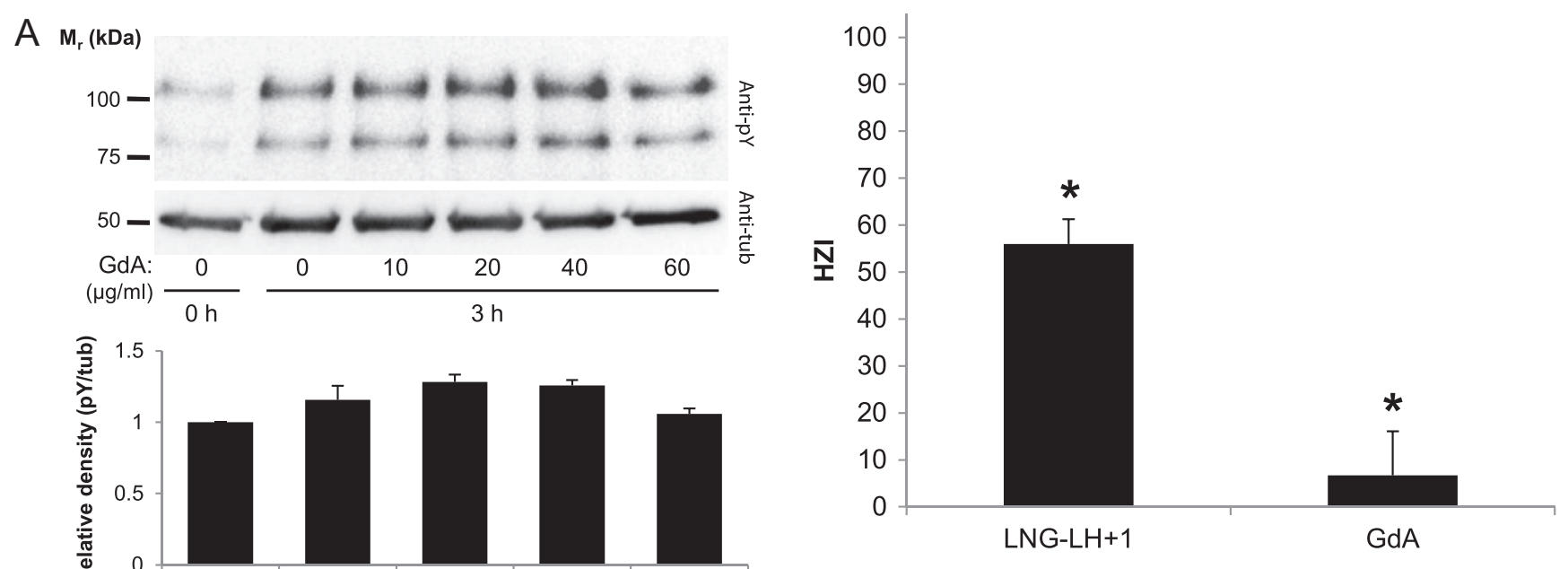

Figure 6 LNG-LH+ 1 and GdA effects on sperm-ZP interaction. Hemizona assays were performed in order to evaluate sperm ability to interact with human ZP after treatments. Results were expressed as the hemizona index $(\mathrm{HZI})$. For $\mathrm{LNG}-\mathrm{LH}+1$ experiments, control hemizonae were incubated with spermatozoa pre-treated with the corresponding CTR-LH +1 UF $(n=3)$, while control hemizonae for GdA evaluations were incubated with spermatozoa in capacitating medium $(n=2)$. ${ }^{*} P<0.05$ vs control. $\mathrm{HZI}=$ (number of test spermatozoa bound to one hemizona/number of control spermatozoa bound to the matching hemizona) $\times 100$.

in women receiving $\mathrm{LNG}$, a synthetic-like progestin. Moreover, the results presented herein indicate changes in sperm functionality that might impact spermatozoafertilizing ability in women treated with LNG.

An interesting new finding in this study was the ability of UF from CTR-LH + 1 to increase sperm protein tyrosine phosphorylation, an observation that was not reproduced in sperm incubated in the presence of $\mathrm{LNG}-\mathrm{LH}+1$. This observation suggests that treatment with LNG may alter the process that provide competent spermatozoa when reach the oviduct ampulla. The reason for this observation cannot be ascertained from the results presented in this study. However, it is known that normally glycodelin S (GdS) from seminal plasma covers the spermatozoa during ejaculation preventing premature activation in the female genital tract (Chiu et al. 2005). In order for capacitation to proceed, GdS must be removed from sperm surface and UF from LNG-LH+1 may not be as efficient as CTR-LH+1 in doing so. In addition, it is known that LNG affects sperm migration through the cervical mucus (Spona et al. 1975), as well as sperm motility, acrosome reaction and zona pellucida binding, particularly when incubated at high concentrations (Yeung et al. 2002, Bahamondes et al. 2003, Munuce et al. 2006). However, LNG given as in emergency contraception reaches a maximum concentration in serum $2 \mathrm{~h}$ after administration (Landgren et al. 1989, Johansson et al. 2002). Although we did not measure LNG concentrations in UF, we consider that LNG in fluids collected three days after treatments were for sure negligible. Therefore,

Interestingly, this is one of the few studies showing how the female genital tract environment might affect the processes aimed at rendering a fertilizing spermatozoon 
we suggest that the effects observed on sperm function should be mediated by changes occurring in the female genital environment after LNG treatment rather than by the progestin itself.

Herein, we have shown that sperm incubated in the presence of UF from LNG-LH+1 had a significant increase in the immotile sperm fraction, suggesting that LNG treatment may be associated with lower motility and hence lower fertilization rates. Furthermore, a significant increase in the acrosome-reacted sperm fraction was found in the presence of LNG-LH+1 when compared to CTR-LH+1 and CTR-LH+12. These results were independent of Pg concentrations in UF, indicating that factors other than this hormone are taking place. In order to fertilize, sperm acrosome reaction must occur in the vicinity of the cumulus-oocyte complex, either during cumulus penetration or at the surface of the ZP (Buffone et al. 2014). Indeed Pg, a natural inducer of capacitation and acrosome reaction (Baldi et al. 2009, Lopez-Torres \& Chirinos 2017), is produced by the cumulus oophorous and is secreted to the follicular fluid in micromolar concentrations (Wen et al. 2010). Instead of this scenario, our observations indicate that, in the presence of Pg-like mediated effects of LNG, a premature acrosome reaction occurring during uterine residency could render a portion of spermatozoa unable to fertilize.

We have previously shown that LNG administration prior to follicle rupture is associated with an increase in serum and intrauterine concentrations of GdA at the time of ovulation (Durand et al. 2010). Our results confirmed that even in the presence of high concentrations of GdA in UF from LNG-LH+1, this glycoprotein does not account for the effects observed on the various sperm physiology parameters studied. Indeed, with the exception of the sperm-ZP interaction, which was significantly inhibited in the presence of LNG-LH +1 and purified GdA, none of the GdA concentrations studied affected sperm tyrosine phosphorylation, motility and acrosome reaction, results that agreed with previous investigations (Oehninger et al. 1995). Nevertheless, we cannot rule out that other LNG-dependent mechanisms, including the expression of other glycodelin species with differential biological activities, may be involved.

To our knowledge, this is the first evidence suggesting LNG-derived effects on the female reproductive tract environment involved in sperm function changes that could impair fertilization. The molecules responsible for such effects have not been identified and require further investigations, but our results support the existence of additional contraceptive mechanisms of LNG other than those affecting ovulation.

\section{Declaration of interest}

The authors declare that there is no conflict of interest that could be perceived as prejudicing the impartiality of the research reported.

\section{Funding}

This study was supported by grant No. 2005-C01-13742 to FL from Consejo Nacional de Ciencia y Tecnología (CONACYT), Mexico.

\section{Acknowledgments}

The authors want to thank Dr Markku Seppala and Dr Riitta Koistinen (University of Helsinki and Helsinki University Central Hospital, Helsinki, Finland) for GdA quantitation in UF and the donation of the purified GdA used in the present work. They are also grateful to Dr Francisco Cano-Vargas and Dr Diego Santillán for their technical support with samples handling and processing.

\section{References}

Aitken RJ \& Nixon B 2013 Sperm capacitation: a distant landscape glimpsed but unexplored. Molecular Human Reproduction 19 785-793. (doi:10.1093/molehr/gat067)

Aquila S \& De Amicis F 2014 Steroid receptors and their ligands: effects on male gamete functions. Experimental Cell Research 328 303-313. (doi:10.1016/j.yexcr.2014.07.015)

Bahamondes L, Nascimento JA, Munuce MJ, Fazano F \& Faundes A 2003 The in vitro effect of levonorgestrel on the acrosome reaction of human spermatozoa from fertile men. Contraception 68 55-59. (doi:10.1016/ S0010-7824(03)00105-7)

Baldi E, Luconi M, Muratori M, Marchiani S, Tamburrino L \& Forti G 2009 Nongenomic activation of spermatozoa by steroid hormones: facts and fictions. Molecular and Cellular Endocrinology 308 39-46. (doi:10.1016/j.mce.2009.02.006)

Buffone MG, Hirohashi N \& Gerton GL 2014 Unresolved questions concerning mammalian sperm acrosomal exocytosis. Biology of Reproduction 90 112. (doi:10.1095/biolreprod.114.117911)

Burkman LJ, Coddington CC, Franken DR, Krugen TF, Rosenwaks Z \& Hogen GD 1988 The hemizona assay (HZA): development of a diagnostic test for the binding of human spermatozoa to the human hemizona pellucida to predict fertilization potential. Fertility and Sterility 49 688-697. (doi:10.1016/S0015-0282(16)59841-0)

Caballero-Campo P, Chirinos M, Fan XJ, Gonzalez-Gonzalez ME, Galicia-Chavarria M, Larrea F \& Gerton GL 2006 Biological effects of recombinant human zona pellucida proteins on sperm function. Biology of Reproduction 74 760-768. (doi:10.1095/biolreprod.105.047522)

Caille AM, Berta CL, Cuasnicu PS \& Munuce MJ 2012 Peritoneal fluid modifies the response of human spermatozoa to follicular fluid. Reproductive BioMedicine Online 24 466-473. (doi:10.1016/j. rbmo.2011.12.010)

Croxatto HB, Brache V, Pavez M, Cochon L, Forcelledo ML, Alvarez F, Massai R, Faundes A \& Salvatierra AM 2004 Pituitary-ovarian function following the standard levonorgestrel emergency contraceptive dose or a single $0.75-\mathrm{mg}$ dose given on the days preceding ovulation. Contraception 70 442-450. (doi:10.1016/j.contraception.2004.05.007)

Chiu PC, Chung MK, Tsang HY, Koistinen R, Koistinen H, Seppala M, Lee KF \& Yeung WS 2005 Glycodelin-S in human seminal plasma reduces cholesterol efflux and inhibits capacitation of spermatozoa. Journal of Biological Chemistry 280 25580-25589. (doi:10.1074/jbc. M504103200)

DasGupta S, O'Toole C, Mills CL \& Fraser LR 1994 Effect of pentoxifylline and progesterone on human sperm capacitation and acrosomal exocytosis. Human Reproduction 9 2103-2109. (doi:10.1093/ oxfordjournals.humrep.a138400)

De Jonge C 2005 Biological basis for human capacitation. Human Reproduction Update 11 205-214. (doi:10.1093/humupd/dmi010)

Durand M, del Carmen Cravioto M, Raymond EG, Duran-Sanchez O, De la Luz Cruz-Hinojosa M, Castell-Rodriguez A, Schiavon R \& Larrea F 2001 On the mechanisms of action of short-term levonorgestrel administration in emergency contraception. Contraception 64 227-234. (doi:10.1016/ S0010-7824(01)00250-5) 
Durand M, Seppala M, Cravioto Mdel C, Koistinen H, Koistinen R, Gonzalez-Macedo J \& Larrea F 2005 Late follicular phase administration of levonorgestrel as an emergency contraceptive changes the secretory pattern of glycodelin in serum and endometrium during the luteal phase of the menstrual cycle. Contraception 71 451-457. (doi:10.1016/j. contraception.2005.01.003)

Durand M, Koistinen R, Chirinos M, Rodriguez JL, Zambrano E, Seppala M \& Larrea F 2010 Hormonal evaluation and midcycle detection of intrauterine glycodelin in women treated with levonorgestrel as in emergency contraception. Contraception 82 526-533. (doi:10.1016/j. contraception.2010.05.015)

Gallo JM, Escalier D, Grellier P, Precigout E, Albert M, David G \& Schrevel J 1991 Characterization of a monoclonal antibody to human proacrosin and its use in acrosomal status evaluation. Journal of Histochemistry and Cytochemistry 39 273-282. (doi:10.1177/39.3.1704391)

Johansson E, Brache V, Alvarez F, Faundes A, Cochon L, Ranta S, Lovern M \& Kumar N 2002 Pharmacokinetic study of different dosing regimens of levonorgestrel for emergency contraception in healthy women. Human Reproduction 17 1472-1476. (doi:10.1093/humrep/17.6.1472)

Kay VJ, Coutts JR \& Robertson L 1994 Effects of pentoxifylline and progesterone on human sperm capacitation and acrosome reaction. Human Reproduction 9 2318-2323. (doi:10.1093/oxfordjournals. humrep.a138445)

Kirton KT \& Hafs HD 1965 Sperm capacitation by uterine fluid or beta-amylase in vitro. Science 150 618-619. (doi:10.1126/ science.150.3696.618)

Landgren BM, Johannisson E, Aedo AR, Kumar A \& Shi YE 1989 The effect of levonorgestrel administered in large doses at different stages of the cycle on ovarian function and endometrial morphology. Contraception 39 275-289. (doi:10.1016/0010-7824(89)90060-7)

Lopez-Torres AS \& Chirinos M 2017 Modulation of human sperm capacitation by progesterone, estradiol, and luteinizing hormone. Reproductive Sciences 24 193-201. (doi:10.1177/1933719116641766)

Lopez-Torres AS, Gonzalez-Gonzalez ME, Mata-Martinez E, Larrea F, Trevino CL \& Chirinos M 2017 Luteinizing hormone modulates intracellular calcium, protein tyrosine phosphorylation and motility during human sperm capacitation. Biochemical and Biophysical Research Communications 483 834-839. (doi:10.1016/j.bbrc.2017.01.010)

Mandelin E, Koistinen H, Koistinen R, Affandi B \& Seppala M 1997 Levonorgestrel-releasing intrauterine device-wearing women express contraceptive glycodelin A in endometrium during midcycle: another contraceptive mechanism? Human Reproduction 12 2671-2675. (doi:10.1093/humrep/12.12.2671)

Munuce MJ, Nascimento JA, Rosano G, Faundes A \& Bahamondes L 2006 Doses of levonorgestrel comparable to that delivered by the levonorgestrel-releasing intrauterine system can modify the in vitro expression of zona binding sites of human spermatozoa. Contraception 73 97-101. (doi:10.1016/j.contraception.2005.06.072)

Oehninger S, Coddington CC, Hodgen GD \& Seppala M 1995 Factors affecting fertilization: endometrial placental protein 14 reduces the capacity of human spermatozoa to bind to the human zona pellucida. Fertility and Sterility 63 377-383. (doi:10.1016/S00150282(16)57372-5)

Riittinen L, Narvanen O, Virtanen I \& Seppala M 1991 Monoclonal antibodies against endometrial protein PP14 and their use for purification and radioimmunoassay of PP14. Journal of Immunological Methods $\mathbf{1 3 6}$ 85-90. (doi:10.1016/0022-1759(91)90253-C)

Saldivar-Hernandez A, Gonzalez-Gonzalez ME, Sanchez-Tusie A, Maldonado-Rosas I, Lopez P, Trevino CL, Larrea F \& Chirinos M 2015 Human sperm degradation of zona pellucida proteins contributes to fertilization. Reproductive Biology and Endocrinology 1399. (doi:10.1186/s12958-015-0094-0)

Spona J, Matt K \& Schneider WH 1975 Study on the action of D-norgestrel as a postcoital contraceptive agent. Contraception 11 31-43. (doi:10.1016/0010-7824(75)90048-7)

Tienthai P, Johannisson A \& Rodriguez-Martinez H 2004 Sperm capacitation in the porcine oviduct. Animal Reproduction Science $\mathbf{8 0}$ 131-146. (doi:10.1016/S0378-4320(03)00134-9)

Wen X, Li D, Tozer AJ, Docherty SM \& Iles RK 2010 Estradiol, progesterone, testosterone profiles in human follicular fluid and cultured granulosa cells from luteinized pre-ovulatory follicles. Reproductive Biology and Endocrinology 8 117. (doi:10.1186/1477-7827-8-117)

World Health Organization 1999 WHO Laboratory Manual for the Examination of Human Semen and Sperm-cervical Mucus Interaction. Cambridge, U.K.; New York, NY: Published on behalf of the World Health Organization by Cambridge University Press.

Yeung WS, Chiu PC, Wang CH, Yao YQ \& Ho PC 2002 The effects of levonorgestrel on various sperm functions. Contraception 66 453-457. (doi:10.1016/S0010-7824(02)00408-0)

Zumoffen CM, Caille AM, Munuce MJ, Cabada MO \& Ghersevich SA 2010 Proteins from human oviductal tissue-conditioned medium modulate sperm capacitation. Human Reproduction 25 1504-1512. (doi:10.1093/ humrep/deq063)

Received 22 May 2017

First decision 12 June 2017

Revised manuscript received 10 July 2017

Accepted 3 August 2017 